\title{
A NECESSIDADE DA EFETIVIDADE DA PARTICIPAÇÃO POPULAR E DO CONTROLE SOCIAL NA ADMINISTRAÇÃO PÚBLICA PARA A CONSOLIDAÇÃO DO PROCESSO DEMOCRÁTICO BRASILEIRO
THE NEED FOR POPULAR PARTICIPATION EFFECTIVENESS AND SOCIAL CONTROL IN PUBLIC ADMINISTRATION FOR THE BRAZILIAN DEMOCRATIC PROCESS CONSOLIDATION

\begin{abstract}
${ }^{1}$ Flávia Couto de Oliveira Contigli
\section{RESUMO}

O presente artigo tem como objetivo buscar a correlação entre participação popular e controle social na administração pública na consolidação do processo democrático brasileiro, sob a ótica da democracia participativa, bem como condições para o aumento desta participação. Na democracia participativa, tendo como marco teórico Bobbio (2006, p.30) e Santos (2002, p.62 e 63), ressalta-se a participação popular como uma das formas de gestão, onde esta exerce um papel importante, o da legitimação das decisões. Este artigo discute os instrumentos de participação popular na administração pública, sem a pretensão de esgotar o tema, bem como tomou como base as definições de Perez (2004), Enterría (1998) e Di Pietro (1993), acrescidas de outros institutos da participação popular. Busca, assim, contribuir incluindo outros instrumentos de participação popular além dos já apontados pelos autores citados, ressaltar as dificuldades e sugerir algumas medidas para minimizar estas dificuldades. A metodologia utilizada para o desenvolvimento do trabalho, dogmática-jurídica, foi desenvolvida através da pesquisa bibliográfica, feita através de um levantamento bibliográfico e leitura analítica sobre o tema-problema.
\end{abstract}

Palavras-chave: Direito administrativo, Administração pública, Participação popular, Controle social, Processo democrático

\begin{abstract}
The current article aims to seek the correlation between popular participation and social control in public administration in the consolidation of the Brazilian democratic process, from the perspective of participatory democracy, as well as conditions for increasing this participation. In participatory democracy, having as the theoretical framework Bobbio (2006, p.30) and Santos (2002, p.62 and 63), it emphasizes public participation as one of the forms of management, where it plays an important role, as legitimating the decisions. This article discusses the ways of popular participation in government, with no claim to exhaust the subject, and was based on Perez settings (2004), Enterría (1998) and Di Pietro (1993), plus other institutes of participation popular. Search thus contribute including other popular participation instruments besides those already mentioned by these authors, emphasize the difficulties and to suggest some measures to minimize them. The methodology used to develop the work, dogmatic and legal, was developed through bibliographic research, done through a literature review and analytical reading on the subject.
\end{abstract}

Keywords: Administrative law, Public administration, Public participation, Social control, Democratic process.

\footnotetext{
${ }^{1}$ Mestranda em Direito - Área de Especialidade Direito Público - pela Universidade FUMEC, Minas Gerais (Brasil). E-mail: flaviaocontigli@hotmail.com
} 


\section{INTRODUÇÃO}

O presente artigo científico tem como objetivo buscar a correlação entre participação popular e controle social na administração pública e a consolidação do processo democrático brasileiro, sob a ótica da democracia participativa.

$\mathrm{Na}$ busca pela consolidação do processo democrático no Brasil, considerando a perspectiva de legitimação das atividades e atuação da Administração Pública brasileira, é de destacada importância o debate sobre a participação popular e o controle social, estes como princípios fundamentais implícitos desta, amparados pela Constituição Federal, ligados diretamente à Administração Pública e suas formas de atuação, bem como para as entidades que compõem essas estruturas.

À despeito da crise contemporânea da democracia representativa brasileira, que repercute em uma grande desconfiança que assola a Administração Pública brasileira e suas instituições, a aproximação e o aumento do interesse da população no acompanhamento da atuação, escolhas e tomada de decisão desta, relacionadas a Administração Pública e os interesses de todos dos indivíduos direta ou indiretamente ligados a uma ou mais decisões, podem não somente contribuir com a recuperação dessa confiança, como também para a legitimação da Administração Pública em si e dos atos praticados pela mesma, além de tornar o processo mais democrático.

Para os autores citados no presente artigo, a ideia de participação popular no contexto do novo modo de ser do Estado contemporâneo está intrinsicamente ligada e se expressa através do exercício da função administrativa. Como bem observado por Odete Medauar, a maior proximidade do Estado com a sociedade num relacionamento de coordenação recíproca se precipita através da participação advinda do interesse desta na administração pública (MEDAUAR, 2003, p. 228-236). Para André Mathiot, através da participação se forma "ponte entre um mundo administrativo muito fechado e cidadãos muito esquecidos", o que diminui ou cria um atalho para aproximação entre estes dois extremos, o mundo administrativo e os cidadãos esquecidos (MATHIOT, 1980, p.251).

A partir de uma maior participação popular na Administração Pública, se estabelece um controle interno à administração advindo de uma ação externa, o que é tratado como importantíssimo para a legitimação do próprio Estado constitucional de caráter democrático, sob a ótica da democracia participativa, com a maior aderência dos cidadãos na atividade administrativa e maior transparência do poder público, sendo um dos instrumentos desta participação a publicidade necessariamente valiosa a essa premissa e alcance do interesse 
público.

Para Norberto Bobbio, o caráter público do poder, como definição para o não secreto ou aberto ao público, tem importante relevância para o que ele denota de democracia participativa, ressaltando através da expressão "poder público em público", onde afirma que "o caráter público do poder, entendido como não-secreto, como aberto ao público, permaneceu como um dos critérios fundamentais para distinguir o Estado constitucional do Estado absoluto", essa transparência imprescindível ao nexo desta com a representação. Ainda que tenham sido criadas ferramentas para se dar publicidade e aproximar governo e governados no sentido anteriormente já mencionado, é patente o campo de oportunidades para se melhorar, uma vez que esses canais de comunicação oficiais ainda são muito segmentados, atingindo a sociedade de forma não muito expressiva (BOBBIO, 2006, p. 101).

De maneira análoga à anterior, Feliciano Benvenuti traz relevância à concretização do poder em ato administrativo como produto do exercício da função, e a extensão das formas processuais ao exercício dessa função administrativa, destacando a importância do objetivo desta última na ação em serviço da comunidade e classificado esse objetivo como a mais alta concepção da Administração (BENVENUTI, 1978, p. 6-23).

Esse princípio aponta igualmente para a diminuição da concentração de poder e a aproximação com a sociedade, notadamente percebido no espírito norteador dos demais pensadores anteriormente citados.

O destaque dado por Odete Medauar ao procedimento como sendo essencial ao fortalecimento dos interesses na busca pelo entendimento dos mesmos antes da tomada de decisão deve ser aqui registrado, em especial num contexto da Administração inserida em sociedade e Estado caracterizados pela complexidade sócio-político-econômica, pelo fato de que isso permite o confronto objetivo e a coexistência de interesses, portanto a uma maior participação e sentimento de pertencimento (MEDAUAR, 2003, p. 224-228).

Igualmente importante para que a análise da necessidade da evolução da participação popular e controle social na administração pública para a consolidação do processo democrático no Brasil possa ser efetiva, se faz necessário relembrar as dificuldades reais dessa participação popular na administração pública, como bem observado por Miguel Sanchez Morón. A premissa de que os problemas de participação popular nesse processo são diferentes para as diferentes classes sociais é um primeiro passo para se evitar a teorização abstrata que uniformiza as situações reais, e que dificulta que os problemas-chave que efetivamente atrapalham essa participação possam ser tratados, permitindo posteriormente o desenvolvimento da mesma (MORÓN, 1987, p. 20). 
As definições e exemplos do que pode ser determinado como participação popular na administração pública e o que está fora desse conceito de participação são importantes para o debate de uma maior participação popular, e para a delimitação das ações que podem corroborar para o desenvolvimento desta possam ser de fato efetivas.

A metodologia utilizada para o desenvolvimento do trabalho, dogmática-jurídica, foi desenvolvida através da pesquisa bibliográfica, feita através de um levantamento bibliográfico sobre o tema-problema, utilizando-se a leitura analítica da doutrina e artigos científicos, para que se chegasse ao desenvolvimento e conclusão, aqui propostos.

\section{A CONSTITUCIONALIZAÇÃO DO DIREITO ADMINISTRATIVO}

Com a constitucionalização do direito houve um efeito expansivo das normas constitucionais, em especial a irradiação do conteúdo material e axiológico, com força normativa aplicada a todo o sistema jurídico. Atualmente, a Constituição figura no centro do sistema jurídico, funcionando como parâmetro de validade para ordem infraconstitucional e também como parâmetro de interpretação de todas as normas do sistema.

Neste contexto, algumas ponderações feitas Luís Roberto Barroso sobre a influência da Constituição no Direito Administrativo e alteração de alguns paradigmas do Direito Administrativo após a constitucionalização do sistema jurídico são relevantes, em especial a redefinição de ideia da supremacia do interesse público sobre o privado, a vinculação do administrador público à Constituição e não apenas à lei ordinária e por último a possibilidade do controle judicial do mérito do ato administrativo (BARROSO, 2003).

Destaca-se também a relação de tensão entre eficiência administrativa, participação dos administrados e controle da Administração Pública pelos outros órgãos de Poder e pela sociedade. Nesse sentido, o princípio constitucional da publicidade começa a se relacionar diretamente com a questão da participação popular e também a fiscalização desta na Administração Pública.

Segundo Norberto Bobbio há uma definição mínima de democracia que é

[...] entendida como contraposta a todas as formas de governo autocrático, é o de considerá-la caracterizada por um conjunto de regras (primárias ou fundamentais) que estabelecem quem está autorizado a tomar as decisões coletivas e com quais procedimentos. (BOBBIO, 2006, p. 30) 
Segundo Boaventura de Sousa Santos, a democracia participativa ocorre na incidência da participação democrática tanto na atuação estatal de coordenação como na atuação dos agentes privados, com intuito de democratizar a esfera estatal.

\begin{abstract}
Nas novas condições a democracia redistributiva tem de ser democracia participativa e participação democrática tem de incidir tanto na actuação estatal de corrodenação como na actuação dos agentes privados, empresas, organizações não governamentais, movimentos sociais cujos interesses e desempenho o Estado coordena. Por outras palavras, não faz sentido democratizar o Estado se simultaneamente não se democratizar a esfera não estatal. Só a convergência dos dois processos de democratização garante a reconstituição do espaço público de deliberação democrática. (SANTOS, 2002, p. 62)
\end{abstract}

Isso reforça as premissas trazidas por Norberto Bobbio da importância da transparência e da participação popular na evolução do Estado absoluto para o Estado constitucional e democrático, ou mesmo também na separação entre ambos. Para ele, a visibilidade ou transparência do poder são conotativos imprescindíveis a qualquer maneira de definição de democracia. Dessa maneira, doravante à imagem da democracia como regime do poder visível, ele define, a partir de um aparente jogo de palavras, o governo da democracia como um governo público em público, sendo o primeiro oposto de privado e o segundo de secreto (BOBBIO, 2006, p. 100-102).

Para Norberto Bobbio, faziam-se igualmente importantes os conceitos de representação e de caráter público do poder, inclusive considerando a representação como o ato de se fazer presente, tornando visível algo que do contrário estaria oculto (BOBBIO, 2006).

Nessa teoria do governo democrático, observa-se também a importância da descentralização para se dar visibilidade pela proximidade ao poder através da aderência a esse movimento, uma vez que não depende somente da publicidade, mas também da proximidade espacial entre governantes e governados o que justifica o poder local, deixando o mínimo de espaço ao poder invisível.

Noberto Bobbio também realça, dentro da linha da participação, a opinião pública como a relevância pública da esfera privada na crítica aos atos do poder público, exigindo a publicidade dos debates tanto políticos como judiciários. Para ele, o grau de relevância da opinião pública como opinião relativa aos atos do poder público é dependente da maior ou menor oferta ao público, entendida como visibilidade, acessibilidade, e, portanto, controlabilidade dos atos de quem detém o poder, entendendo a publicidade como categoria tipicamente iluminista, tendo a metáfora da luz no contraste entre poder visível e o invisível (BOBBIO, 2006). 


\section{OS INSTRUMENTOS DE PARTICIPAÇÃO POPULAR NA ADMINISTRAÇÃO PÚBLICA}

Primeiramente se faz necessário delimitar as formas de participação popular na Administração Púbica, balizando, também, o que não faz parte da participação popular nesta.

Assim, apontando o que não faz parte da participação popular na Administração Pública, onde considera-se que a intervenção do particular para defender direitos pessoais e individuais, bem como na reivindicação de questões pessoais não é uma forma de participação popular.

Outras formas que também não podem ser consideradas como participação popular na Administração Pública são os cidadãos que se tornam funcionários públicos mediante concurso público, bem como os cidadãos que são convocados para comprimento de serviços obrigatórios, como o militar, a prestação de serviço público por um cessionário, por ser este o exercício privado de funções públicas e esta participação ter motivação econômica e não o interesse da sociedade.

De forma sintética recorre-se a Marcos Augusto Perez:

Identificamo-nos, nesse passo, com García de Enterría, para incluir no conceito de participação no conceito de participação popular na Administração Pública somente aqueles instrumentos que permitam ao particular tomar parte nas decisões, na execução e no controle das atividades administrativas, no interesse da sociedade, uti socius, uti cives. Identificamo-nos, igualmente, com a posição de Odete Medauar, excluindo do conceito dos institutos de participação popular na Administração Pública: "a) o exercício privado de funções públicas, como ocorre na concessão de serviço; b) a atuação do indivíduo na defesa direta de direitos próprios perante a Administração. (PEREZ, 2004)

Passa-se então a analisar agora as formas de participação popular, através da classificação desenvolvida por Eduardo Garcia de Enterría:

a) participação orgânica: inserção dos cidadãos, enquanto tais (não como funcionários ou políticos), em órgãos da estrutura do poder Público; ex. as corporações públicas; administração não corporativa; técnicas de representação de interesses e técnica de colaboração de especialistas.

b) participação funcional: atuação cidadã fora do aparato administrativo, mas em atividades materialmente públicas, com o auxílio ou concordância da Administração; ex. consultas públicas; denúncias; exercício de ações populares; petições e propostas;

c) participação cooperativa: atuação do cidadão como sujeito privado, sem exercer função materialmente pública, mas em atividades de interesse geral, com apoio do Poder Público. Ex. atividades de entidades de utilidade pública, entre outras. (ENTERRÍA, 1998, p.82-93) 
Em contraponto a elaborada por Maria Sylvia Zanella Di Pietro:

\begin{abstract}
a) participação direta: a realizada sem a presença de intermediários eleitos; exemplifica com o direito de ser ouvido e a enquete (consulta à opinião pública sobre assunto de interesse geral);
\end{abstract}

b) participação indireta: a realizada através de intermediários, eleitos ou indicados; exemplifica com a participação popular em órgão de consulta, a participação popular em órgão de decisão, a participação por meio do ombudsman e a participação por via do Poder Judiciário. (PIETRO, 1993, P. 134-138)

Após definir as formas de participação popular na Administração Pública, se faz necessário apontar os institutos de participação popular, que possibilitam o cidadão a participar e efetivam esta participação.

a. Conselhos e comissões participativos: colegiados que reúnem representantes da Administração Pública e da sociedade, podendo esses ter igualdade de representação ou não, que participam do processo decisório de uma determinada área ou assunto relacionado a interesses da Administração. Podem estes ser de duas formas meramente consultivo ou deliberativo. Garantido por várias Leis no âmbito federal, estadual e municipal.

b. Audiência pública: sessão aberta ao público em geral, onde será discutido um assunto que ainda seja objeto de decisão pela Administração. Nestas os cidadãos participantes podem fazer sugestões, criticas, apontamentos, pedir esclarecimentos e até mesmo contribuir com o tema discutido. Garantido por várias Leis no âmbito federal, estadual e municipal.

c. Consulta pública: relativa a matérias de interesse geral onde é oportunizado aos interessados fazer por escrito suas considerações, podendo estas versar sobre esclarecimentos, sugestões, críticas e informações sobre o tema, devendo ser amplamente divulgada e ter um prazo razoável.

d. Orçamento participativo: tem previsão legal no âmbito estadual e municipal, não sendo obrigatório a todos os Estados e Municípios, bem como não está previsto no âmbito federal. Ocorre no processo de elaboração de Leis Orçamentarias e consiste na realização de audiências públicas onde representantes de conselhos deliberativos e cidadãos opinam sobre o projeto de lei orçamentaria que será enviado ao Legislativo pelo Executivo. Instituto que permite a participação democrática dos cidadãos em opinar, discutir e tomar decisões sobre orçamentos públicos, inclusive decidindo onde este orçamento será utilizado. 
e. Ouvidoria pública: exercido por um representante popular eleito ou indicado pelo Legislativo com a finalidade de fiscalizar a atuação da Administração, sendo presente em vários órgãos públicos.

f. Organizações sociais: são pessoas jurídicas de direito privado, que não possuem fim lucrativo, que atuam e executam atividades administrativas normalmente nas áreas de ensino, tecnológicas, pesquisa científica, meio ambiente, saúde e cultura.

g. Plebiscito: consulta popular sob determinado tema relevante, onde o povo decide, podendo tratar de matéria constitucional, legislativa ou administrativa, sendo sua vigência está condicionada a decisão popular, que ratificara ou rejeitara a proposta

h. Denúncia aos Tribunais ou Conselhos de Contas: conforme Diogo de Figueiredo Moreira Neto (NETO, 1997, p.11-23).

i. Reclamação relativa à prestação de serviços públicos: conforme Diogo de Figueiredo Moreira Neto (NETO, 1997, p.11-23).

j. Provocação de inquérito civil: conforme Diogo de Figueiredo Moreira Neto (NETO, 1997, p.11-23).

k. Assessoria Externa: conforme Diogo de Figueiredo Moreira Neto (NETO, 1997, p.11-23).

A inclusão de maior número de institutos de participação popular, classificados por autores diferentes, tem como intuito de fomentar a participação popular e não as restringir às divergências doutrinárias.

\section{AS DIFICULDADES NA EFETIVAÇÃO DA PARTICIPAÇÃO POPULAR}

Existem problemas e dificuldades na efetivação da participação popular na Administração Pública, que minimizam seus efeitos, bem como empobrecem o próprio processo democrático.

Cabe aqui citar o trecho de Norberto Bobbio para ilustrar a crise da democracia representativa e como esta afeta, inclusive, a participação popular:

\footnotetext{
[...] o ausente crescimento da educação para a cidadania, segundo a qual o cidadão investido do poder de eleger os próprios governantes acabaria por escolher os mais sábios, os mais honestos e os mais esclarecidos dentro os seus concidadãos, pode ser considerado como o efeito da ilusão derivada de uma concepção excessivamente benévola do homem como animal político: o homem persegue o próprio interesse tanto no mercado econômico como no político. Mas ninguém pensa hoje em contestar a democracia sustentando, como se vem fazenda há anos, que o voto é uma mercadoria que se cede ao melhor ofertante. (BOBBIO, 2006, p. 21-22)
} 
A ideia não é na verdade de se exaurir este tema-problema, bem como o rol de dificuldades apresentado não é taxativo e sim exemplificativo.

Uma das dificuldades citada por Norberto Bobbio e abordado no trecho acima deve ser destacado, que é a falta ou pouca educação para a cidadania, pois não há esforços políticos, administrativos ou até mesmo jurídicos, no sentido de fomentar uma educação que forme verdadeiros cidadãos, conscientes dos seus direitos e deveres perante a sociedade, com capacidade para exigir e participar popularmente (BOBBIO, 2006, p. 21-22).

O problema da má qualidade da educação no Brasil gera outras dificuldades para efetivação da participação popular, uma vez que o cidadão que não é educado, não reconhece as possibilidades de exercer seus direitos de participação na Administração Pública, tampouco seus deveres.

A falta de instrução neste sentido também gera apatia e muitas vezes impede o próprio cidadão de participar, uma vez que este não tem sequer as condições mínimas para compreender o que está sendo discutido, o que lhe alija do processo de participação popular, sendo necessário lembrar que mesmo nos dias atuais ainda existem inúmeras pessoas analfabetas.

Outro problema ainda ligado a educação é que vários institutos de participação popular na Administração Pública são muito formais e requerem um conhecimento específico, o que retira grande parte da população deste processo. Neste sentido, uma questão relevante e que impede o exercício da participação inclusive cidadãos que tem interesse em participar dos processos de participação popular é a falta ou restrita divulgação destes e a pouca transparência nos atos da Administração, além da falta de orientação dada aos cidadãos que querem participar. A propaganda oficial governamental busca, na maioria absoluta das vezes, ressaltar os feitos do governo da situação em detrimento da publicidade das formas de participação popular na fiscalização e controle da Administração pública.

Outros fatores que dificultam os próprios processos de participação popular no Brasil, são as características da sociedade brasileira contemporânea, que é muito heterogênea, complexa, onde todos têm que ser incluídos na participação, indiferentemente de sua condição de minoria, ainda agravada pela grande desigualdade social.

A própria procedimentalização dos diversos institutos de participação são um dilema para ambos os lados, uma vez que a Administração Pública tem que desenvolver formas mais eficientes e que abranja o maior número de cidadãos participantes nos processos de participação popular, o que não tem sido fácil pelas características da sociedade atual acima apontadas, por outro lado a própria sociedade tem que se organizar para maximizar sua 
participação popular e torna-la eficiente dentro do processos de participação, garantindo assim também sua efetividade.

No Brasil ainda se enfrenta a burocracia excessiva que acompanha quase todos os processos e institutos de participação popular, a Administração Pública e mesmo na área jurídica como um todo. Ocorre, ainda, a defasagem em relação a efetivação dos direitos fundamentais distribuídos de forma homogênea e adequada, como a educação, saúde, moradia e previdência, que deveriam ser prioritários. Os direitos fundamentais são exigência e concretização do princípio da dignidade da pessoa humana.

Por fim deve-se ressaltar uma questão cultural do Brasil que remonta aos tempos de colônia que é a política e a corrupção que impede a participação popular ou desestimula que esta ocorra, bem como em decorrência da crise da representação torna a sociedade cética, desestimulando esta de participar uma vez que a mesma não acredita que sua participação gere resultados efetivos.

\section{SUGESTÕES PARA ULTRAPASSAR OS PROBLEMAS NA EFETIVAÇÃO DA PARTICIPAÇÃO POPULAR}

\subsection{O princípio da transparência e da informação}

A Constituição atual é composta por um sistema aberto de princípios e regras, nos quais os princípios de igualdade, dignidade da pessoa humana, pluralismo político e probidade administrativa desempenham um papel central.

Entre eles há um princípio muito importante o da transparência e da informação em relação aos atos da Administração Pública, uma vez que através destes os cidadãos poderão fiscalizar estes atos.

Cabe citar aqui dois trechos do texto "Transparência Administrativa e Novas Tecnologias: o Dever de Publicidade, o Direito a ser Informado e o Princípio Democrático”, de Têmis Limberger:

\footnotetext{
A informação possui uma nota distinta no Estado Democrático de Direito se comparado ao modelo liberal. Para este último é uma consequência política do exercício de certas liberdades individuais. Nos Estados democráticos, a livre discussão é um componente jurídico prévio à tomada de decisão que afeta à coletividade e é imprescindível para sua legitimação. Por isso, para Ignácio Villaverde Menéndez, no Estado democrático, a informação é credora de uma atenção particular por sua importância na participação do cidadão no controle e na crítica dos assuntos públicos. Não somente se protege a difusão, como sucedia no Estado liberal, mas também se assegura a própria informação, porque o processo de comunicação é essencial à democracia. O ordenamento jurídico no Estado democrático se assenta no
} 
princípio geral da publicidade, devendo o sigilo ser excepcional e justificado. Esse preceito é extraído com base no princípio da publicidade e do direito a ser informado do cidadão.

\begin{abstract}
A transparência é uma via de mão dupla: de um lado a administração tem o dever de dar publicidade aos seus atos e, por outro, o cidadão tem o direito a ser informado. Deste modo, por meio da informação disponível por meio eletrônico, desenvolve-se um controle preventivo, estimula-se a participação popular, torna-se o exercício do poder mais transparente e, portanto, mais democrático. Evita-se que o cidadão desinformado dos assuntos públicos constitua-se num idiótes (conforme a nomenclatura dos gregos). Com a diminuição dos desvios de dinheiro gerados pela corrupção é possível viabilizar a melhoria das prestações sociais, que podem ser oferecidas à população, ou seja, concretizam-se direitos. (Disponível em: <http://bibliotecadigital.fgv.br/ojs/index.php/rda/article/viewFile/42471/41191.>)
\end{abstract}

Parte das dificuldades apontadas acima, como a falta de divulgação, transparência nos atos a Administração podem ser resolvidos efetivando estes princípios, uma vez que na sociedade moderna o que não faltam são meios de comunicação, sendo assim ao dar maior transparência e informação possibilita-se que o cidadão fiscalize, participe nos processos de participação popular, além de efetivar a o Estado Democrático, a democracia participativa e dar maior legitimidade aos atos da Administração Pública.

\title{
5.2 A educação
}

Uma das formas mais eficientes para sanar os problemas acima apontados é a educação dos cidadãos para maior participação. Para que se possibilite a participação popular de forma efetiva e eficiente primeiramente tem que se dar condições aos cidadãos de participar das discussões e para isso é necessário que esse tenha uma educação de qualidade, não só no sentido clássico, mas no sentido obter conhecimento para compreender seus direitos e deveres como cidadão, os direitos e deveres dos agentes públicos e da Administração Pública, entre eles o de fiscalizar e participar das decisões públicas, bem como saber a usar os instrumentos que permitem esta participação popular.

Para que esta transformação na educação ocorra também é necessária vontade política que não vem sendo aplicada no Brasil, uma vez que ao se educar e formar cidadãos consequentemente haverão cobranças da efetivação dos direitos e cumprimento das normas de forma ética e comprometida, por parte da Administração Pública e em todas as esferas das funções do Executivo, Legislativo e Judiciário.

Quando o cidadão não possui educação de qualidade este fica fora do processo de participação popular ou não tem instrumentos intelectuais suficientes para exercer este direito de forma plena e efetiva. 
Um outro problema grave que pode ser resolvido ou pelo menos suavizado através da educação é própria corrupção, que no Brasil possui um enorme impacto sobre a vida da população, uma vez que a ética faz parte da educação e se contrapõem a corrupção. Este ponto, em especifico, não é o foco de debate deste artigo e, portanto, deve ser aprofundado em um outro momento.

Através da educação também se minimizam as desigualdades sociais, além de atribuir dignidade à pessoa, tornando mais efetiva a participação popular. Todo esse processo possui ligação intrínseca com tudo que foi discutido aqui até o momento, e é parte inseparável dos fatores que podem fomentar a evolução da participação popular e do controle social na administração pública para a efetivação e consolidação do processo democrático brasileiro.

\section{CONCLUSÃO}

Por tudo que foi colocado aqui, podemos concluir que apesar da importância da correlação entre participação popular e controle social na administração pública para a consolidação do processo democrático brasileiro, o Brasil é uma democracia ainda jovem e que muito ainda tem de ser feito para que esta participação seja cada vez mais efetiva para consolidação do Estado democrático, em especial no que tange a participação popular no controle da Administração pública, até como forma de legitimá-la, na busca de uma democracia realmente participativa.

Obviamente não é difícil perceber alguma evolução no campo da transparência, que é um dos componentes necessários à base do desenvolvimento da participação popular nesse processo, principalmente com a criação de portais de informação da Administração pública, abertura de arquivos secretos e sua disponibilização, entre outras ações que vem sendo tomadas.

A participação popular na democracia brasileira ainda é muito voltada apenas ao comparecimento das pessoas às urnas, na escolha de seus representantes, tanto do legislativo, quanto do executivo nas esferas municipal, estadual e federal. Entretanto, como foi possível constatar ao longo deste artigo, seja pelo conceito amplo de democracia dos autores aqui ressaltados, ou pelos próprios fundamentos constitucionais inerentes ao Estado democrático de direito brasileiro, é possível concluir que há uma necessidade clara de se expandir essa participação buscando um desenvolvimento pleno da mesma que a torne mais efetiva, preenchendo as lacunas debatidas no presente texto, objetivando a legitimidade tão necessária ao próprio processo da Administração pública. 
Entretanto, o que também pode-se concluir ao longo da análise aqui tecida foi que paralelamente deveria ocorrer para que a participação popular pudesse ser verdadeiramente efetiva no processo de fiscalização e acompanhamento dos trabalhos da Administração pública, e que talvez seja o fator mais preponderante para que este desenvolvimento pudesse acontecer de maneira plena, não tem sido o foco de atenção de vontade política, que é a preparação da sociedade, e sua capacitação para que a mesma possa ser consciente e competente para isso.

Ficou latente na discussão aqui proposta que a necessidade de que o poder público seja "público", não somente no sentido de ser apenas publicado ou tornado disponível para o conhecimento da coletividade, mas a inutilidade que esta publicidade e acesso à informação publicada ocorra sem a maioria da população, nesse caso brasileira, não esteja preparada e conscientizada da importância de sua participação lúcida e engajada nesse processo de fiscalização e acompanhamento.

Ao correlacionar os conceitos retratados no presente artigo, ressaltou-se a profundidade do desafio que é o abismo intelectual necessário à maioria da população brasileira para que essa efetividade de participação, pincipalmente no papel fiscalizador do cidadão, possa acontecer, em especial as bases fundamentais de civismo, interesse no bem da coletividade, além de outras premissas que deveriam vir ainda antes do despertar pelo interesse da importância dessa participação nesse sentido específico.

Ficou claro após a análise da bibliografia aqui escolhida a importância de se correlacionar os conceitos abordados e trabalhados, na busca por novos caminhos que levem à evolução e maturidade da democracia brasileira, entendendo que se quer continuar, do presente para o futuro, no modelo atualmente vigente de Estado constitucional, preconizado pelos autores tratados.

Foi possível concluir também que as condições para que o aumento da participação popular no controle da Administração pública brasileira devem ser foco de interesse político dos vários níveis governamentais, uma vez que as poucas iniciativas já efetuadas no passado não tiveram continuidade apesar do sucesso em termos de engajamento da população, como no caso do orçamento participativo - escolha das obras ou ações a serem realizadas e acompanhamento dos dispêndios previamente planejados - e os portais governamentais de transparência. As razões para que esse engajamento não evoluísse devem ser foco de novos e futuros artigos.

O grande destaque dado ao debate aqui proposto foi de buscar correlacionar os conceitos aqui abordados, e para que se pudesse fazê-lo foi necessário primeiramente entendê- 
los, para posteriormente poder propor maneiras de evolução na participação e premissas para a preparação da mesma.

Ao analisar as formas de participação popular na Administração Pública, do controle exercido pelo cidadão e suas formas sobre as atividades da Administração Pública, foi possível visualizar o quanto o Brasil está ainda distante de todo esse processo e da concretização do interesse público aplicado em favor da coletividade, bem como da aderência às normas tomadas, que deveriam contar com a participação do cidadão. É possível entender que para contornar os problemas que levam à falta de conscientização da importância da participação nesse processo, é preciso realizar essa análise das condições preliminares que devem estar presentes e são tão necessárias para que essa participação possa ser entendida e dada como importante pela própria população, e que só pode ser feita a partir de uma educação para esse objetivo.

Fica explícita a crise da representatividade no processo democrático brasileiro pelas lacunas de participação e conscientização para a participação aqui apresentadas, assim como foram analisadas algumas razões para que a situação atual se concretizasse, e também ações que poderiam ser tomadas no futuro para mitigar a continuidade da situação atual. Ainda foram levantadas sugestões importantes para a superação das dificuldades que foram analisadas como sendo as causas mais prováveis das dificuldades na evolução da participação popular na Administração pública, principalmente no papel fiscalizador e acompanhador dos processos administrativos, além de melhorias que poderiam ser tomadas, com o devido interesse do poder público, para que a consolidação do processo democrático brasileiro pudesse avançar em termos de efetividade a partir do maior interesse coletivo em participar desse acompanhamento e fiscalização sobre os processos inerentes à Administração pública, porém não sem antes despertar para a importância de compreender as razões pelas quais essa participação se faz essencial à legitimação da própria Administração pública, a partir de seus preceitos fundamentais de constituição.

\section{REFERÊNCIAS}

BARROSO, Luís Roberto. Agências reguladoras. Constituição, transformações do Estado e legitimidade democrática. São Paulo. 2003.

BENVENUTI, Feliciano. L'amministrazione oggetivata: un nuovo modello. Rivista trimestrale de scienza della Amministrazione, ano XXV, p.6-23. Jan-mar 1978. 
BOBBIO, Norberto. O futuro da democracia. Trad. Marco Aurélio Nogueira. São Paulo: Paz e Terra, 2006.

ENTERRIA, Eduardo Garcia de y FERNÁNDEZ, Tomás-Ramón. Curso de Derecho Administrativo, 5 ed. Madrid: Civitas, 1998, v. 2.

DI PIETRO, Maria Sylvia Zanella. Participação Popular na Administração Pública, In: Revista Trimestral de Direito Público, São Paulo, n. 1, 1993, pp. 128-139.

LIMBERGER, Têmis: Transparência Administrativa e Novas Tecnologias: o Dever de Publicidade, o Direito a ser Informado e o Princípio Democrático. Disponível em: <http://bibliotecadigital.fgv.br/ojs/index.php/rda/article/viewFile/42471/41191.> Acesso em: 28 de jul. 2015.

MATHIOT, André. Bureaucratie et democratie. Pages de doctrine. Paris: LGDJ, 1980 (Trabalho publicado pela primeira vez em Études et documents du Conseil d’État, 1961)

MEDAUAR, Odete. O direito administrativo em evolução. São Paulo: Revista dos Tribunais, 2003.

MEDAUAR, Odete. Controles internos da Administração Pública. Disponível em: <http://www.revistas.usp.br/rfdusp/article/viewFile/67131/69741>. Acesso em: 3 de ago. 2015

MEDAUAR, Odete. Segurança Jurídica e Confiança Legítima. Disponível em: <http://revistas.unibrasil.com.br/cadernosdireito/index.php/direito/article/viewFile/700/656>. Acesso em: 3 de ago. 2015.

MÓRON, Miguel Sanchez. La Participación del Ciudadano en la Administración Pública. Madrid, Centro de Estudios Constitucionales, 1980.

NETO, Diogo de Figueiredo Moreira. Audiências públicas. Revista de Direito Administrativo, v. 210, p. 11-23, 1997.

PEREZ, Marcos Augusto. A administração pública democrática: institutos de participação popular na administração pública. Belo Horizonte: Fórum, 2004.

SANTOS, Boaventura de Sousa. Reinventar a Democracia. Lisboa: Gradiva, 2002. 